\title{
Effects of Rice Hush as Substitute for Fine Aggregate in Concrete Mixture
}

\author{
Tomas U. Ganiron Jr \\ College of Architecture, Qassim University, Buraidah City \\ tomasuganironjr@gmail.com
}

\begin{abstract}
This experimental study aimed to analyze the effect of rice husks as fine aggregate in terms of water-cement ratio, quality and size of coarse aggregate, and consistency of the mixture and determine how rice husk differ with other ordinary concrete mix as fine aggregate in terms of water adsorption, compressive strength, tensile strength and modulus of elasticity. This also aims to help contribute to the industry in saving the environment, to encourage the government to find solutions regarding the disposal to landfills of waste materials and save the environment, to provide new knowledge to the contractors and developers on how to improve the construction industry methods and services by using rice husk, and to sustain good product performance and meet recycling goals. Observations from the tests performed were conducted in the laboratory where precise data were gathered and completely attained
\end{abstract}

Keywords: Aggregates, construction material, concrete mixture, rice husk, waste material

\section{Introduction}

Much of the natural building movement is unpinned by a renaissance of the blended trade and profession known as master building essentially, it is the shift way from highly more overlapping, if not entirely enmeshed roles. The holistic approach to design the building offered closer and more creative kinship with materials, it allow better person response to subtleties of the site and interface of building forms. It respects the unique talents of its participants in a building process and affords opportunity for a greater self-expression in planning, execution and embellishment. A master-building climate encourages innovation and is the ideal setting for the growth of the alternative building. It has also spawned a revival of building as craft.

Construction technologies being develop and refined the builders featured in their responses to environmental and social issues surrounding the extraction of row materials from nature and their use in construction for built environment. Although these materials and method have traditionally been considered "primitive" and therefore inferior to more highly processes materials in terms of safety, durability, performance, occupants health, and comfort with respect to environmental issue, consumption of environmental products and energy within the construction industry has created a significant demand for raw materials and for production thereby contributing to the many environmental problems associated with diverse ecosystem.

Ethically, are raised by the facts, that the average lifestyles of the people affluence nation directly impact the lives of the world poorest people both of these benefits and detriment, by creating the demand for the export of their resources and agricultural products. Socially, it benefit accrue from reaffirmation of communal bonds by those who participate in community construction project. Strategically, for reducing negative 
environment impact is not stated explicit, although it is being noted that the emission of particulates from earthen finishes can something high.

Workability, strength, and durability are three basics properties of concrete [1]. Amount of useful internal work necessary to overcome the internal friction to produce full compaction is termed as Workability. Size, shape, surface texture and grading of aggregates, water-cement ratio, use of admixtures and mix proportion are important factors affecting workability. Strength is to bear the desired stresses within the permissible factor of safety in expected exposure condition. The factor influencing the strength are: quality of cement, water-cement ratio, grading of aggregates, degree of compaction, efficiency of curing, curing temperature, age at the time of testing, impact and fatigue. Durability is sustenance of shape, size and strength; resistance to exposure conditions, disintegration and wearing under adverse conditions. Variation in concrete production, loading conditions in service life and subsequent attack by the environment factors are main deteriorating factor of concrete [1, 2]. Properly compacted and cured concrete used in RCC continues to be substantially water tight and durable till capillary pores and micro-cracks in the interior are interconnected to form pathways up to surface.

Durability is mainly influenced by environmental exposure condition, freezingthawing, contact to aggressive chemicals, type and quality of constituent materials, water-cement ratio, workability, shape and size of the member, degree of compaction, efficiency of curing, effectiveness of cover concrete, porosity and permeability [3]. During service life of structures, penetration of water and aggressive chemicals, carbonation, chloride ingress, leaching, sulphate attack, alkali-silica reaction and freezing-thawing are resulting deterioration $[3,4]$. Loading and weathering inter link voids and micro-cracks present in transition zone and network of same micro cracks gets connected to cracks on concrete surface which provides primary mechanism of the fluid transport to interior of concrete. Subsequent increase of penetrability leads to easy ingress of water, oxygen, carbon dioxide and acidic ions etc., into concrete resulting cracking, spalling, loss at mass, strength and stiffness.

Low permeability is key to durability and it is controlled by factors like watercement ratio, degree of hydration, curing, entrapped air voids, micro cracks due to loading and cyclic exposure to thermal variations[5]. Admixture improves workability, compaction, strength, impermeability and resistance to chemical attack. For this study durability is interpreted in terms of porosity, moisture movement, surface strength, ultra sound pulse velocity and elasticity modulus of concrete. Optimum use of Rice Husk Ash (RHA), obtained by open field burning method, is decided for improving workability, strength and durability of concrete [6].

RHA, produced after burning of Rice husks ( $\mathrm{RH}$ ) has high reactivity and pozzolanic property. Indian Standard code of practice for plain and reinforced concrete, IS 4562000, recommends use of RHA in concrete but does not specify quantities [7]. Chemical compositions of RHA are affected due to burning process and temperature. Silica content in the ash increases with higher the burning temperature. As per study by Houston, D. F. (1972) RHA produced by burning rice husk between 600 and $700^{\circ} \mathrm{C}$ temperatures for 2 hours, contains $90-95 \% \mathrm{SiO}_{2}, 1-3 \% \mathrm{~K}_{2} \mathrm{O}$ and $<5 \%$ unburned carbon [8]. Under controlled burning condition in industrial furnace, conducted by Mehta, P. K. (1992), RHA contains silica in amorphous and highly cellular form, with 50-1000 $\mathrm{m}^{2} / \mathrm{g}$ surface area. So use of RHA with cement improves workability and stability, reduces heat evolution, thermal cracking and plastic shrinkage [8]. This increases strength development, impermeability and durability by strengthening transition zone, 
modifying the pore-structure, blocking the large voids in the hydrated cement paste through pozzolanic reaction. RHA minimizes alkali-aggregate reaction, reduces expansion, refines pore structure and hinders diffusion of alkali ions to the surface of aggregate by micro porous structure [5, 8].

Portland cement contains 60 to $65 \% \mathrm{CaO}$ and, upon hydration, a considerable portion of lime is released as free $\mathrm{Ca}(\mathrm{OH})_{2}$, which is primarily responsible for the poor performance of Portland cement concretes in acidic environments. Silica present in the RHA combines with the calcium hydroxide and results excellent resistance of the material to acidic environments. RHA replacing 10\% Portland cement resists chloride penetration, improves capillary suction and accelerated chloride diffusivity [9].

Pozzolanic reaction of RHA consumes $\mathrm{Ca}(\mathrm{OH})_{2}$ present in a hydrated Portland cement paste, reduces susceptible to acid attack and improves resistance to chloride penetration. This reduces large pores and porosity resulting very low permeability. The pozzolanic and cementitious reaction associated with RHA reduces the free lime present in the cement paste, decreases the permeability of the system, improves overall resistance to $\mathrm{CO}_{2}$ attack and enhances resistance to corrosion of steel in concrete [10, 11]. Highly micro porous structure RHA mixed concrete provides escape paths for the freezing water inside the concrete, relieving internal stresses, reducing micro cracking and improving freeze-thaw resistance.

Rice husks is a substitute material to fine aggregate in mixing mortar and grout to the concrete having an alternative option in the industrial materials [12]. The main objective of this new approach will give a partial replacement of the craft and will determined the ability and benefits to the concrete when substrate. However, the pattern of development have a sustainable ecological health as the building material used and reduced the economic value to industrial product and provides an insulation value to the structure particularly to the changing of weather condition. The tests will successfully enough that this substitute materials included to the development process.

\section{Literature Review}

RHA as pozzolan is an effective admixture for cement and used as additives to reduce corrosion and increased durability of concrete structure, the technologies being transferred initially the central Luzon owing to its being the rice transfer campaign in implementing agency DOST- PCIERD as funding agency under the agreement the Rice Husk will be supplied any region affluence of Rice Husks and have the proper allowance for expansion and contraction of Rice Husks in conjunction with the other materials which assembles and integrated $[14,15]$.

In popularity of Rice Husks, it may attribute to its durability and low production cost. In the Philippines approximately 3,442,655 metric tons generated each year [12, 14]. In the University of the Philippines Building Research Services initiated studies in collaboration of Department of Science and Technology, the study focused in the used for the non- bearing blocks intended for low income housing program [13]. The Philippine Council for Industry and Energy Research and AUF program hopes for assist small scale, contractor, and entrepreneur and rice mill owners, the project envisioned to provide socio - economic benefits to technology adapters to environmental management in the region [16].

The use of RHA contributed not only, to the production of concrete of a higher quality and lower cost, but also the reduction of carbon dioxide $\left(\mathrm{CO}_{2}\right)$ emissions from the production of cement. The partial replacement of cement by RHA will result in lower energy consumption associated with the production of cement [17] 
The reference also addresses the economic development, urbanization, higher living standards, tighter environmental regulations, and consolidation in the rice milling industry are reducing some of the traditional uses of husk, and creating new opportunities for husk utilization $[15,17]$. Studies have shown that RHA resulting from the burning of rice husk at control temperatures have physical and chemical properties that meet ASTM (American Society for Testing and Materials) Standard C 618-94a. At burning temperatures of $550{ }^{0} \mathrm{C}-800{ }^{0} \mathrm{C}$, amorphous silica is formed, but at higher temperatures crystalline silica is produced [15, 19]. The silica content is between 90 and 96\%. The particular chemical and physical properties are shows the diffraction analysis, which indicates that the RHA mainly consists of amorphous materials [18]

The use of RHA in the production of high-performance and high-durable concrete has been presented in several papers $[18,19]$. The significant findings were as follows: i) Substantial reduction in mass loss on exposure to hydrochloric solutions. ii) Considerable reduction in alkali-silica and sulfate expansions. iii) Higher frost resistance of non-air entrained RHA concrete compared to similar mixtures of silica

Rice husk is reported to be a cement alternative and an ideal additive to decrease corrosion and enhance durability of concrete structures [20]. Annual rice husk production nationwide exceeds two million tons. Generally discarded as agro-waste, about 17-25 percent of rice husk weight remains as ash when burnt, which can be used as a pozzolana to replace as much as 50 percent of ordinary Portland cement. Silica present in ash reacts with lime in the presence of water to form calcium [16. 20].

\section{Methodology}

\subsection{Materials}

3.1.1. Rice Hush Ash: Rice husk was burnt approximately 60 hours under uncontrolled combustion process. The burning temperature was within the range 600 to $8500^{\circ} \mathrm{C}$. The ash obtained was ground in a ball mill (Figure 1) for 1 hour and its appearance color was gray (Figure 2). Their physical and chemical characteristics were determined according to the AASHTO Standards (Table 1).

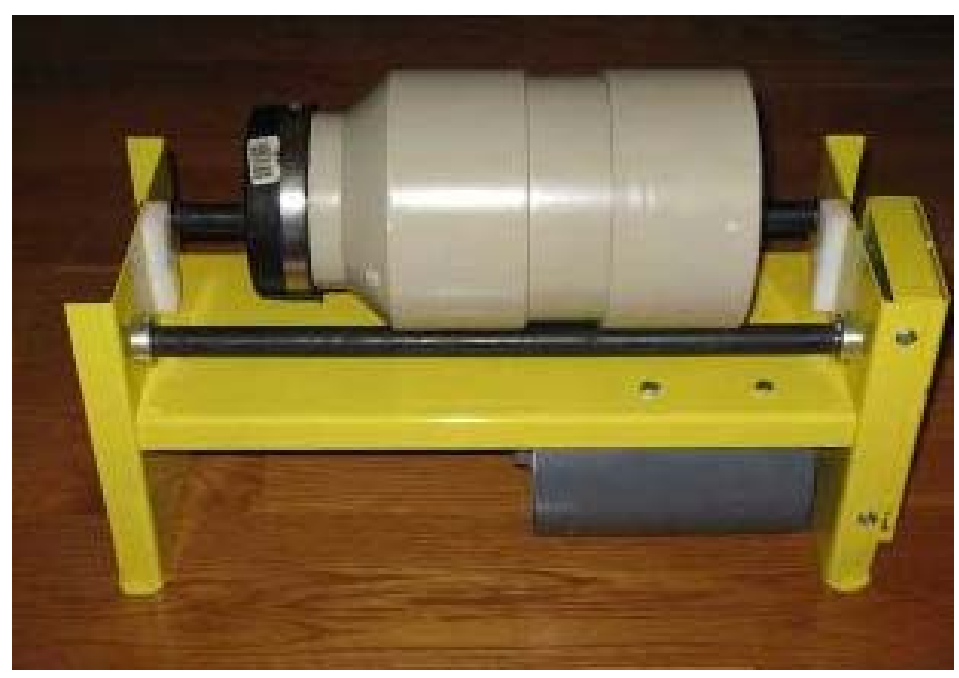

Figure 1. Ball Mill 


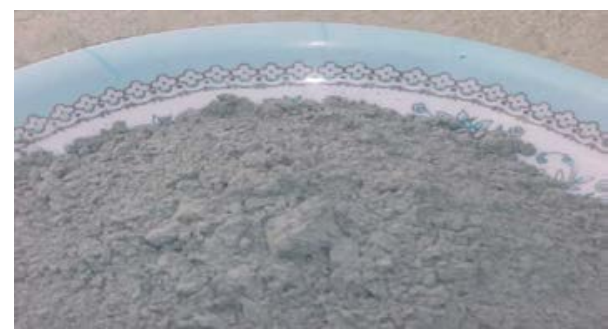

Figure 2. Sample of RHA after 1 hour of Grounding

Table 1 Physical and Chemical Properties of RHA

\begin{tabular}{|c|c|c|}
\hline \multicolumn{2}{|c|}{ Blaine Specific Surface $\left(\mathrm{cm}^{2} / \mathrm{g}\right)$} & 13150 \\
\hline \multicolumn{2}{|c|}{ Specific Gravity $\left(\mathrm{cm}^{2} / \mathrm{g}\right)$} & 2.21 \\
\hline \multicolumn{1}{|c|}{ Mean Particle size $(\mu \mathrm{m})$} & 10.61 \\
\hline \multicolumn{1}{|c|}{ Passing \# 325 $(\%)$} & 95.10 \\
\hline \multirow{4}{*}{$\begin{array}{c}\text { Chemical } \\
\text { Ingredients }\end{array}$} & $\mathrm{SiO}_{2}$ & 90.16 \\
\cline { 2 - 3 } & $\mathrm{Fe}_{2} \mathrm{O}_{3}$ & 0.41 \\
\cline { 2 - 3 } & $\mathrm{Al}_{2} \mathrm{O}_{3}$ & 0.11 \\
\cline { 2 - 3 } & $\mathrm{CaO}$ & 1.01 \\
\cline { 2 - 3 } & $\mathrm{MgO}$ & 0.27 \\
\cline { 2 - 3 } & $\mathrm{Sl}_{2} \mathrm{O}_{3}+\mathrm{Fe}_{2} \mathrm{O}_{3}$ & 0.12 \\
\cline { 2 - 3 } & $\mathrm{SiO}_{2}+\mathrm{Al}_{2} \mathrm{O}_{3}+$ & 0.52 \\
\cline { 2 - 3 } & $\mathrm{Fe}_{2} \mathrm{O}_{3}$ & 0.93 \\
\cline { 2 - 3 } & $\mathrm{Na}_{2} \mathrm{O}$ & 0.01 \\
\cline { 2 - 3 } & $\mathrm{K}_{2} \mathrm{O}$ & 0.65 \\
\hline
\end{tabular}

According to the chemical characteristics, the RHA has high levels of silicon dioxide, approximately $93 \%$, and the specific gravity is $2.21 \mathrm{~cm}^{2} / \mathrm{g}$. It also showed a very distinct peak corresponding to crystalline silica. The reason for this behavior is the long time combustion process and the high temperature of burning. The average particle size distribution was $10.61 \mu \mathrm{m}$. Thus the RHA is finer than cement and should be expected to work not only a pozzolanic role, but also a micro filler effect.

3.1.2. Cement: The cement type used in this research was high early strength Portland cement. All their characteristics were according to ASTM physical and chemical properties of cement were listed in Table 2.

Table 2. Physical and Chemical Properties of Cement

\begin{tabular}{|c|c|c|}
\hline \multicolumn{2}{|c|}{ Blaine Specific Surface $\left(\mathrm{cm}^{2} / \mathrm{g}\right)$} & 5900 \\
\hline \multicolumn{2}{|c|}{ Specific Gravity $\left(\mathrm{cm}^{2} / \mathrm{g}\right)$} & 2.01 \\
\hline \multicolumn{2}{|c|}{ Initial Time Setting } & $2: 45$ \\
\hline \multirow{3}{*}{$\begin{array}{l}\text { Compressive } \\
\text { Strength } \\
\text { (MPa) }\end{array}$} & 3 days & 34.3 \\
\hline & 14 days & 37.7 \\
\hline & 28 days & 42.4 \\
\hline \multirow{8}{*}{$\begin{array}{l}\text { Chemical } \\
\text { Ingredients }\end{array}$} & $\mathrm{SiO}_{2}$ & 21.78 \\
\hline & $\mathrm{Fe}_{2} \mathrm{O}_{3}$ & 2.01 \\
\hline & $\mathrm{Al}_{2} \mathrm{O}_{3}$ & 8.01 \\
\hline & $\mathrm{CaO}$ & 47.23 \\
\hline & $\mathrm{MgO}$ & 3.26 \\
\hline & $\mathrm{SO}_{3}$ & 3.25 \\
\hline & $\mathrm{Na}_{2} \mathrm{O}$ & 0.15 \\
\hline & $\mathrm{K}_{2} \mathrm{O}$ & 0.11 \\
\hline
\end{tabular}


3.1.3. Aggregates: The fine aggregate used is a natural sand with fineness modulus of 2.25 and specific gravity $2.58 \mathrm{~g} / \mathrm{cm}^{3}$. The coarse aggregate (basalt rock) has maximum size of $19 \mathrm{~mm}$ and specific gravity $2.96 \mathrm{~g} / \mathrm{cm}^{3}$.

3.1.4. Superplasticizer: A superplasticizer of third generation for concrete was used. This superplasticizer is suitable for the production of high performance concrete. It facilitates extremely high water reduction, high flow ability as well as internal cohesiveness.

\subsection{Composition of Concrete Mixtures}

Table 3 shows the used mixture proportions of concrete. Three dosages of CCA, 8\% (mixture E) and 15\% (mixture F) in substitution to the cement, and a control mixture (mixture D) had been used. The slump test was fixed in $120 \pm 20 \mathrm{~mm}$, therefore, for the mixtures $\mathrm{D}$ and $\mathrm{E}$, the dosage of superplasticizer was $0.35 \%$ of binder mass. For the mixture $\mathrm{F}$, the dosage of superplasticizer was $0.45 \%$.

Table 3. Composition of Concrete Mixtures

\begin{tabular}{|c|c|c|c|c|c|c|}
\hline \multirow{2}{*}{ Cement } & \multirow{2}{*}{ Sand } & \multirow{2}{*}{$\begin{array}{c}\text { Coarse } \\
\text { Aggregate }\end{array}$} & \multirow{2}{*}{ W/C } & \multicolumn{3}{|c|}{ Cement $\left(\mathrm{kg} / \mathrm{m}^{3}\right)$} \\
\cline { 5 - 7 } & & & & Mixture D & Mixture E & Mixture F \\
\hline 1 & 1.10 & 2.11 & 0.41 & 520.0 & 494.0 & 478.0 \\
\hline
\end{tabular}

After that, had been molded cylindrical specimens of dimensions $10 \times 20 \mathrm{~cm}$ and tested to the simple compressive strength, splitting tensile strength, water absorption by immersion and elasticity modulus. The tests had been carried through with ages of 7 and 28 days, with curing in humid chamber

\section{Results and Discussion}

\subsection{Water Absorption}

The water absorption is shown in Table 4 and Figure 3. The results reveal that higher substitution amounts results in lower water absorption values, it's occur due to the RHA is finer than cement. Adding $15 \%$ of RHA to the concrete, a reduction of $32.4 \%$ in water absorption is observed when compared to mixture $\mathrm{D}$.

Table 4. Absorption Test (\%)

\begin{tabular}{|c|c|c|}
\hline Mixture & 7 days & 28 days \\
\hline $\mathrm{D}$ & 3.23 & 2.28 \\
\hline $\mathrm{E}$ & 3.11 & 2.13 \\
\hline $\mathrm{F}$ & 3.09 & 1.98 \\
\hline
\end{tabular}




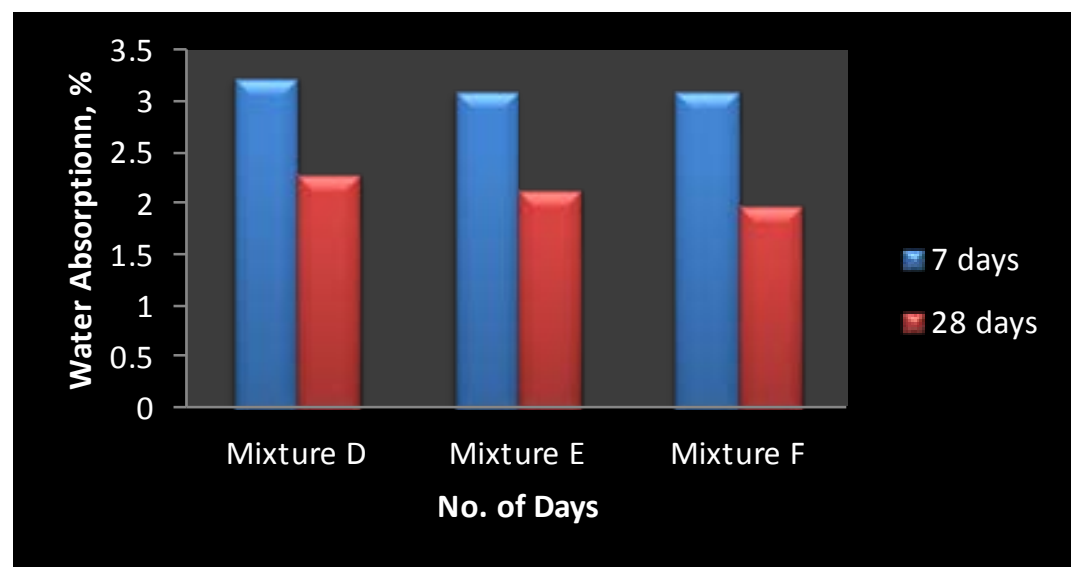

Figure 3. Results of Water Absorption Test

\subsection{Compressive Strength}

The compressive strength is shown in Table 5 and Figure 4. The addition of RHA causes an increment in the compressive strength due to the capacity of the pozzolana, of fixing the calcium hydroxide, generated during the reactions of hydrate of cement. All the replacement degrees of RHA increased the compressive strength. For a 7\% of RHA, $15 \%$ of increment is verified when compared with mixture D.

\section{Table 5. Compressive Strength (MPa)}

\begin{tabular}{|l|l|l|}
\hline Mixture & 7 days & 28 days \\
\hline D & 55.1 & 57.2 \\
\hline E & 61.6 & 70.1 \\
\hline F & 54.8 & 63.7 \\
\hline
\end{tabular}

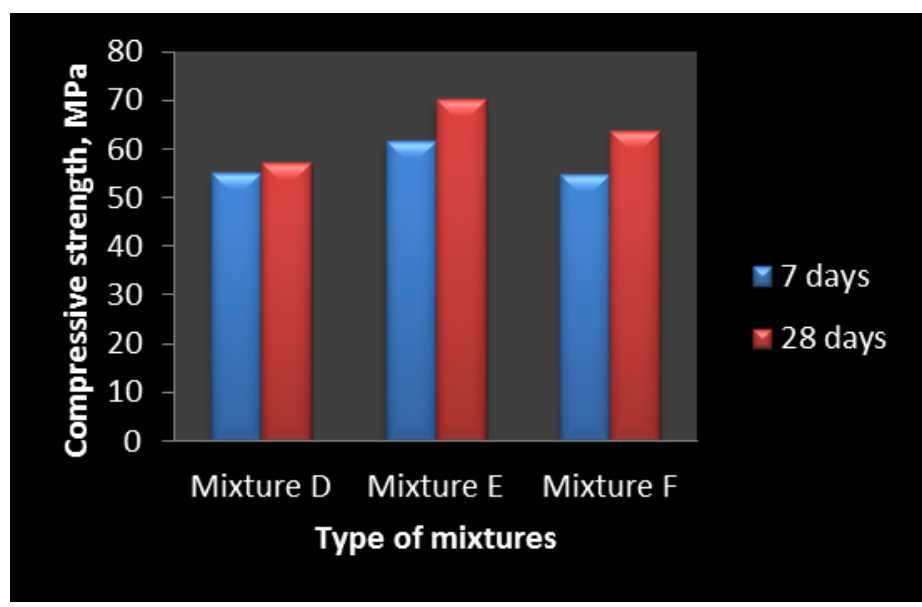

Figure 4. Results of Compressive Strength

\subsection{Tensile Strength}

The results of splitting tensile strength are shown in Table 6 and Figure 5. All the replacement degrees of RHA researched, achieve similar results in splitting tensile 
strength. According to the results, may be realized that there is no interference of adding RHA in the splitting tensile strength.

\section{Table 6. Tensile Strength (MPa)}

\begin{tabular}{|c|c|c|}
\hline Mixture & 7 days & 28 days \\
\hline D & 5.55 & 6.67 \\
\hline E & 5.78 & 6.98 \\
\hline F & 5.51 & 6.91 \\
\hline
\end{tabular}

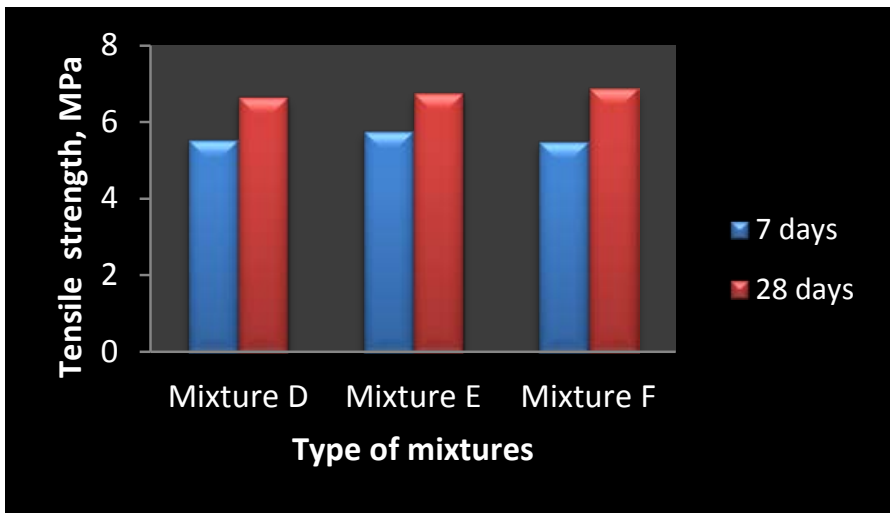

Figure 5. Results of Tensile Strength

\subsection{Elastic Modulus}

The elasticity modulus is shown in Table 7 and Figure 6. All samples studied have similar results in elasticity module. A decreasing in the module is realized when the levels of RHA are increasing.

Table 7. Elastic Modulus(GPa)

\begin{tabular}{|c|c|c|}
\hline Mixture & 7 days & 28 days \\
\hline D & 41.12 & 51.19 \\
\hline E & 43.89 & 43.92 \\
\hline F & 43.23 & 43.12 \\
\hline
\end{tabular}

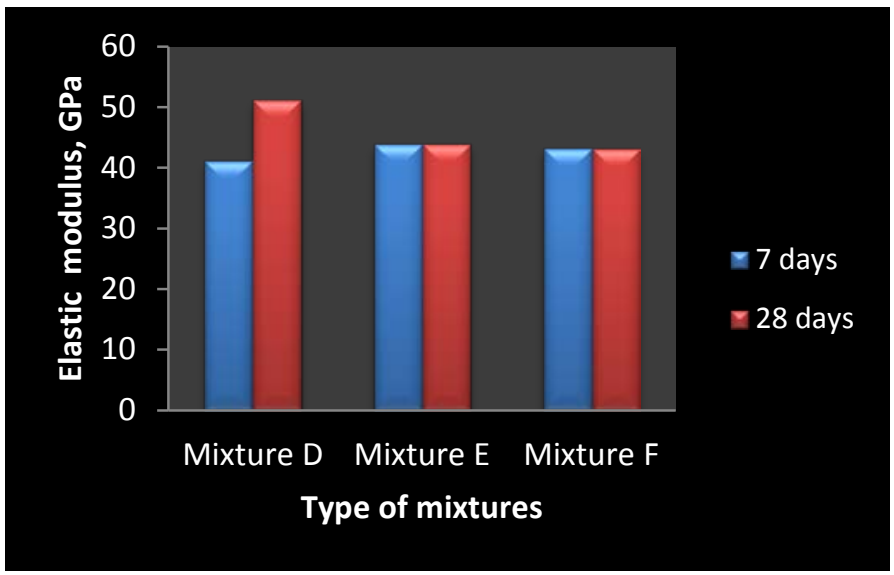

Figure 6. Results of Elastic Modulus 


\section{Conclusion}

This paper was conducted to study the effect of RHA as substitute for fine aggregate in concrete mixture. The properties of concrete containing RHA had been successfully studied. The use of RHA in civil construction, besides reducing the environmental polluters' factors, may bring several improvements for the concrete characteristics. The water cement ratio is the factor affecting the quality of the concrete with a substitute of rice husks as fine aggregate. Adding RHA to concrete, a decreasing in water absorption was verified. A reducing of $32.4 \%$ was observed when compared to control sample. An increment of $15 \%$ was obtained when added $7 \%$ of RHA. According to the results of splitting tensile test, all the replacement degrees of RHA researched, achieve similar results. This may be realized that there is no interference of adding RHA in the splitting tensile strength. The rice husk is applicable to concrete for interior concrete wall. Moreover, the application was intended to non- entrained placement. The wet weather conditions cause deterioration of husks that affect the stability of the concrete.

\section{Appendix}
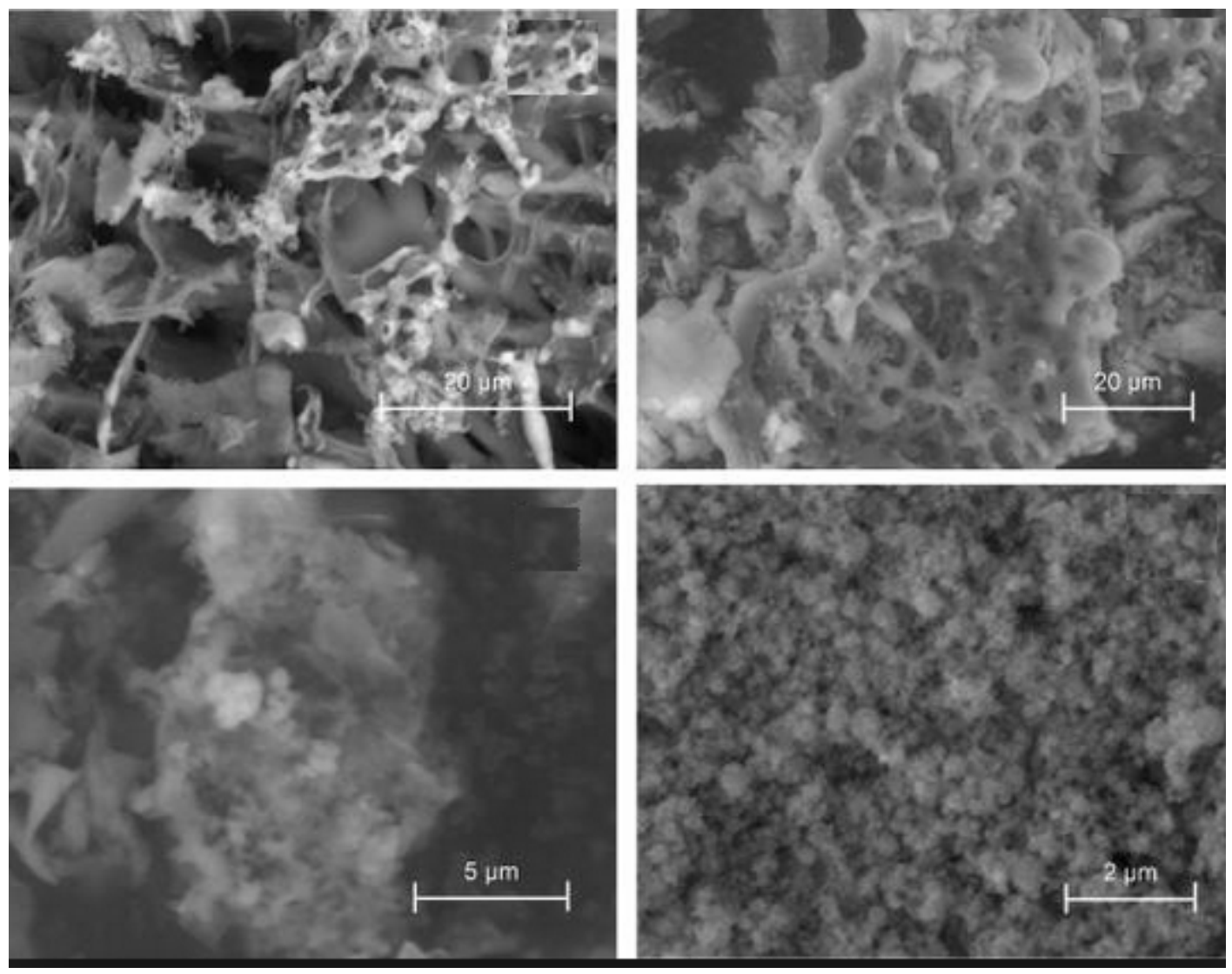

Figure 7. Images of RHA 

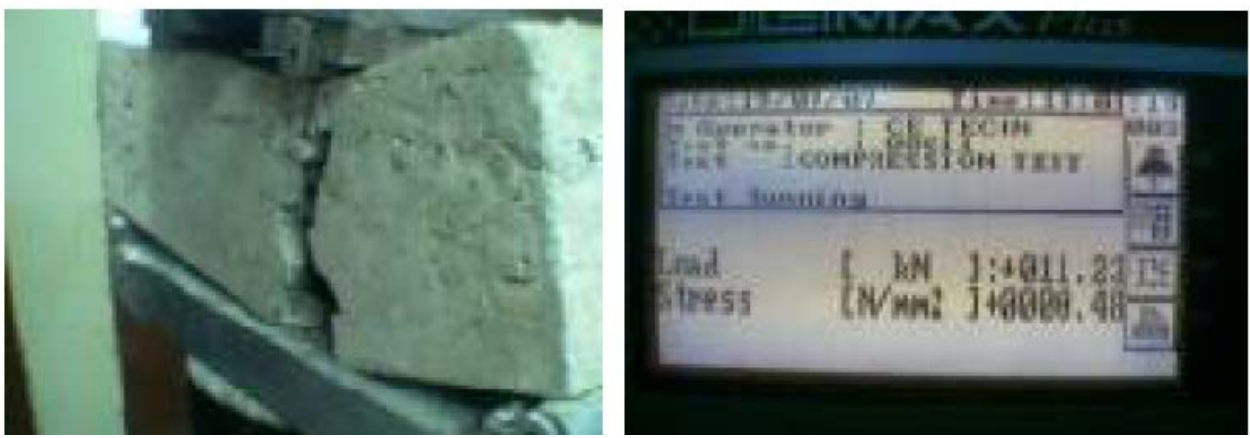

Figure 8. Testing of Specimen

\section{References}

[1] M. P. Kumar, "Use of Activated Carbons prepared from Sawdust and Rice-husk for Adsorption of Acid Dyes: A Case Study of Acid Yellow 36”. Dyes and Pigments, vol. 56, no. 3, (2003), pp. 239-249

[2] V. Vadivelan and K. V. Kumar, "Equilibrium, Kinetics, Mechanism, and Process Design for the Sorption of Methylene Blue onto Rice Husk”, Journal of Colloid and Interface Science, vol. 286, no. 1, (2005), pp. 90100.

[3] U. Kumar and M. Bandyopadhyay, "Sorption of Cadmium from Aqueous Solution using Pretreated Rice Husk”, Bioresource Technology, vol. 97, no. 1, (2006), pp. 104-109.

[4] K. Wong, "Removal of $\mathrm{Cu}$ and $\mathrm{Pb}$ by Tartaric Acid Modified Rice Husk from Aqueous Solutions", Chemosphere, vol. 50, no. 1, (2003), pp. 23-28.

[5] P. Mehta, "Properties of blended Cements made from Rice Husk Ash”, ACI Journal Proceedings, vol. 74, no. 9, (1977).

[6] N. Yalcin and V. Sevinc, "Studies on Silica obtained from Rice Husk”, Ceramics International, vol. 27, no. 2, (2001), pp. 219-224.

[7] K. Srinivasan, N. Balasubramanian and T. V. Ramakrishna, "Studies on Chromium Removal by Rice Husk Carbon”, Indian Journal of Environmental Health, vol. 30, no. 4, (1988), pp. 376-387.

[8] H. Premalal, H. Ismail and A. Baharin, "Comparison of the Mechanical Properties of Rice Husk powder filled Polypropylene Composites with Talc filled Polypropylene Composites”, Polymer Testing, vol. 21, no. 7, (2002), pp. 833-839.

[9] T. G. Chuah, "Rice Husk as a Potentially Low-Cost Bio-sorbent for Heavy Metal and Dye Removal: An Overview”, Desalination, vol. 175, no. 3, (2005), pp. 305-316.

[10] N. Bishnoi, “Adsorption of Cr (VI) on Activated Rice Husk Carbon and Activated Alumina”, Bioresource Technology, vol. 91, no. 3, (2004), pp. 305-307.

[11] M. H. Zhang and V. M. Malhotra, "High-performance Concrete incorporating Rice Husk Ash as a Supplementary Cementing Material”, ACI Materials Journal, vol. 93, no. 6, (1996).

[12] H. S. Yang, "R.-H. Flour filled Polypropylene Composites; Mechanical and Morphological Study", Composite Structures, vol. 63, no. 3, (2004), pp. 305-312.

[13] L. Armesto, “Combustion Behaviour of Rice Husk in a Bubbling Fluidized Bed”, Biomass and Bioenergy, vol. 23, no. 3, (2002), pp. 171-179.

[14] K. S. Low and C. K. Lee, “Quaternized Rice Husk as Sorbent for Reactive Dyes”, Bioresource Technology, vol. 61, no. 2, (1997), pp. 121-125.

[15] W. T. Tsai, M. K. Lee and Y. M. Chang, "Fast Pyrolysis of Rice Husk: Product Yields and Compositions”, Bioresource Technology, vol. 98, no. 1, (2007), pp. 22-28.

[16] K. Krishnani, "Biosorption Mechanism of Nine Different Heavy Metals onto Bio-matrix from Rice Husk", Journal of Hazardous Materials, vol. 153, no. 3, (2008), pp. 1222-1234.

[17] M. Fang, "Experimental Study on Rice Husk Combustion in a Circulating Fluidized Bed”, Fuel Processing Technology, vol. 85, no. 11, (2004), pp. 1273-1282.

[18] V. M. Srivastava, I. O. Mall and I. M. Mishra, "Characterization of Mesoporous Rice Husk Ash (RHA) and Adsorption Kinetics of Metal Ions from Aqueous Solution onto RHA”, Journal of Hazardous Materials, vol. 134, no. 1, (2006), pp. 257-267.

[19] A. H. Mahvi, A. Maleki and A. Eslami, "Potential of Rice Husk and Rice Husk Ash for Phenol Removal in Aqueous Systems”, American Journal of Applied Science, vol. 1, no. 4, (2004), pp. 321-326.

[20] T. Z. Liou, "Preparation and Characterization of Nano-structured Silica from Rice Husk", Materials Science and Engineering, vol. A 364, no. 1, (2004), pp. 313-323. 


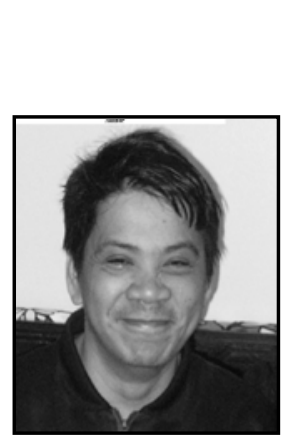

\section{Author}

Tomas U. Ganiron Jr. This author obtained his Doctor of Philosophy in Construction Management at Adamson University (Philippines) in 2006, and subsequently earned his Master of Civil Engineering major in Highway and Transportation Engineering at Dela Salle University-Manila (Philippines) in 1997 and received Bachelor of Science in Civil Engineering major in Structural Engineering at University of the East (Philippines) in 1990. He is a registered Civil Engineer in the Philippines and Professional Engineer in New Zealand. His main areas of research interest are construction engineering, construction management, project management and recycled waste materials. Dr. Ganiron Jr is a proud member of professional organizations like the Institution of Engineers-Australia and American Society of Civil Engineer. He is also very active in other professional groups like Railway Technical Society of Australasia and Australian Institute of Geoscientists where he became committee of Scientific Research. He has given invited or keynote lectures at a number of international conferences and has received the ASTM Award CA Hogentogler for 2008 in New Zealand and Outstanding Researcher for 2013 in Qassim University. 
International Journal of Advanced Science and Technology Vol.58, (2013) 